\title{
Research on Inheritance and Innovation of Chinese Medicine Culture in Colleges and Universities
}

\author{
Yong Zhao ${ }^{1, \mathrm{a}}$, Jun $\mathrm{Ma}^{2, \mathrm{~b}}$, Manli Chen*3,c \\ ${ }^{1}$ School of Management, Hubei University of Chinese Medicine, Wuhan, China \\ ${ }^{2}$ College of Acupuncture and Orthopedics, Hubei University of Chinese Medicine, Wuhan, China \\ ${ }^{3}$ School of Management, Hubei University of Chinese Medicine, Wuhan, China
}

\begin{abstract}
With the development of Internet information technology, traditional Chinese medicine culture is stepping into people's life in a new way. As the main front of talent training and cultural inheritance, TCM colleges and universities play an important role in cultural development and innovation. At present, there are some problems in TCM colleges and universities, such as the lack of prominent cultural characteristics, the decline of students' cultural confidence and sense of identity, and the insufficient application of Internet technology. Therefore, it is suggested to integrate classical culture learning and practical training, integrate superior resources inside and outside the school, strengthen cultural propaganda and information technology development and utilization, and other measures to promote TCM colleges and universities to fulfill the mission of the university, and promote the inheritance and innovation of TCM culture.
\end{abstract}

\section{Introduction}

In the context of the rapid development of social economy and information technology, people's living standards have been continuously improved, and traditional Chinese medicine(TCM) is playing an increasingly important role in maintaining people's health. In particular, the proposal of "Healthy China" strategy and COVID-19's surprise attack, the thousands of years of TCM thinking concept of "preventing disease" and the experience of fighting "epidemic", once again show its unique cultural charm and medical value to the world. As the cradle of TCM talents training and the main base for traditional culture inheritance and innovation, TCM colleges and universities should grasp the characteristics and advantages of TCM culture, build their own university culture around TCM culture, and then shoulder the historical responsibility of TCM culture inheritance and innovation[1].

\section{The Main Problems Faced by the Cultural Inheritance and Innovation of TCM Colleges and Universities}

In recent years, colleges and universities of TCM have bravely assumed important responsibilities and missions, and actively promoted talent training and cultural dissemination. According to statistics from the Ministry of Education, the enrollment of undergraduate and junior college students in medical colleges and universities from 2017 to 2019 was 490,471, 511,953 and 595,719, showing an increasing trend year by year. The proportion of the number of medical colleges and universities in the number

ae-mail: 977969050@qq.com

c* Corresponding author. e-mail: manli@hbtcm.edu.cn of ordinary colleges and universities has increased from $6.46 \%$ in 2017 to $6.52 \%$ in 2019 (see Table1). The construction of high-quality talents in medical colleges and universities is growing, which provides intelligence support for the inheritance and innovation of Chinese medicine culture. Meanwhile, the talent training mode of domestic medical college alliance is becoming more and more mature, and the scale of Confucius Institutes of TCM in foreign countries is expanding. The training mode of the alliance of medical colleges and universities in China is mature, The scale of Confucius Institute of TCM abroad is expanding. According to statistics, as of December 2019, Chinese colleges and universities of TCM have strengthened international cooperation on TCM education through various channels. More than 10,000 international students majoring in TCM are recruited each year. About 1,500 amateur TCM teaching institutions send about 30,000 Chinese medicine technicians to the world every year, and the pace of Chinese medicine culture going out is accelerating.

Table1. Enrollment number of undergraduate and junior college students in universities and medical colleges

\begin{tabular}{c|c|c|c}
\hline \multirow{2}{*}{ Classification } & \multicolumn{3}{|c}{ Year } \\
\cline { 2 - 4 } & 2017 & 2018 & 2019 \\
\hline $\begin{array}{c}\text { General institutions of higher } \\
\text { learning }\end{array}$ & 7593579 & 7892793 & 9135189 \\
$\begin{array}{c}\text { Among them: medical } \\
\text { colleges }\end{array}$ & 490471 & 511953 & 595719 \\
$\begin{array}{c}\text { Ratio of Enrollment in } \\
\text { Medical Colleges to } \\
\text { Enrollment in Universities } \\
(\%)\end{array}$ & 6.46 & 6.49 & 6.52 \\
\hline
\end{tabular}


TCM colleges and universities have made some achievements in the internal inheritance and innovation of TCM culture as well as foreign exchange and cooperation. However, the inheritance and innovation of TCM culture itself is a long-term and complicated systematic work, and naturally, many problems have been exposed in the inheritance of TCM culture in colleges and universities, mainly manifested in the following aspects:

\subsection{Decline in Cultural Identity of TCM}

With the development of economic globalization and cultural diversification, students' confidence in TCM culture is gradually declining, and TCM is facing a serious identity crisis. First of all, TCM is more complicated and difficult to understand. Compared with TCM, western medicine is easier to "enter". For college students with limited time and energy, western medicine has an advantage in terms of time cost[2]. At the same time, the teaching form of teachers in medical colleges is relatively simple, and the training of practical skills is relatively lacking. Many Chinese medicine students' professional thoughts are unstable. In addition, modern western medicine, with its advantages of "quick curative effect and convenient use of medicine", poses a great threat to the development of TCM, and students' theoretical beliefs in TCM are gradually shaken. Secondly, under the influence of multiculturalism, Chinese medicine students lack the ability to distinguish and think independently, and the three outlooks are vulnerable to the impact of foreign bad culture, which leads to the gradual decline of their recognition of TCM culture. What's more, some students apply for TCM colleges and universities in order to get a higher salary in the medical industry in the future, which is not due to the identification of TCM culture[3]. Therefore, how to enhance the students' self-confidence and sense of identity in TCM culture has become the important and difficult point for TCM colleges and universities to promote the inheritance and innovation of TCM culture.

\subsection{Lack of Cultural Characteristics and TCM Thinking}

In the long process of development, TCM has formed a complete theoretical system of knowledge and rich clinical practice experience, which is China's precious material and spiritual wealth. However, due to the influence of teaching mode and supporting services, TCM institutions failed to maximize the value of TCM cultural treasure house. First, the teaching mode of modern TCM colleges and universities is mainly based on "college education" and mainly relies on "one-to-many" classroom teaching, which tends to cause the lack of perceptual understanding and practical skills of TCM students. Second, it pays more attention to curriculum offering than system connection, which fails to help students establish the knowledge organization level and thinking mode from concept to theory and then to practice[4]. Third, the supporting facilities for the construction of campus material culture and spiritual civilization are not perfect, and the cultural heritage is insufficient. Compared with other nontraditional Chinese medicine colleges and universities, the campus cultural environment construction of TCM colleges and universities is monotonous, and the development convergence phenomenon is obvious, which fails to reveal the characteristics of TCM culture.

\subsection{Slow Internationalization}

TCM is traditional, national, modern, and global. With the growing demand for health care, disease prevention and treatment, it is inevitable that TCM will go to the world[5]. As of December 2019, TCM has spread to 183 countries and regions around the world, with 15 Confucius Institutes and Classrooms, 53 international standards on TCM and 388 cross-border cooperation projects established, according to China Economic Net. TCM culture is entering more and more countries and regions through TCM colleges and universities. However, in the process of building a community with a shared future for mankind and sharing the achievements of civilization, the contribution of TCM colleges and universities in promoting the internationalization of TCM culture is far from enough. First, the cultivation of high-quality talents with solid basic theory and strong cross-cultural communication ability of TCM is insufficient, and the lack of compound talents seriously hinders the effect of external communication. Second, there is a single carrier and form for the dissemination of TCM culture, and the application of new media technology is rare. It is not enough to rely solely on talent exchanges, paper newspapers and books for dissemination. The third is that the communication ideas are mainly "one-way communication" and do not distinguish between regional and cultural differences, failing to realize the adaptation to local conditions. In terms of communication content, it focuses on "what I want to communicate" rather than "what the other side needs", which puts the cart before the horse and fails to meet the audience's demand for information[6].

\section{Thoughts on the Cultural Inheritance and Innovation of TCM Colleges and Universities}

\subsection{Inherit the Classic Culture and Focus on the Unity of Knowledge and Action}

First of all, we must strengthen personnel training and cooperation with institutions. General Secretary $\mathrm{Xi}$ Jinping once pointed out that "development is the top priority, talent is the top resource, and innovation is the top driving force". Talents are the key to the inheritance and innovation of TCM culture. As the training base of highquality talents, TCM colleges and universities have the ability and mission to cultivate backbone talents of TCM, with the purpose that the excellent culture of TCM can be passed on from generation to generation, which can provide a steady stream of vitality for the inheritance and innovation of culture. One is to enhance students' sense of 
cultural identity and self-confidence in Chinese medicine. Colleges and universities should adhere to the cultural value orientation of TCM as the goal, take the cultivation of TCM thinking as the key, and take various ways and methods to strengthen the cultural confidence education of Chinese medicine students[7]. On the one hand, TCM colleges and universities should use classroom teaching, academic forums, TCM culture museums and other forms to optimize the talent training model, strengthen students' self-confidence in TCM culture through multiple paths, and finally stimulate the sense of mission and responsibility to inherit and carry forward the excellent culture of TCM. On the other hand, we should build a campus culture brand with Chinese medicine characteristics, and create a good Chinese medicine cultural atmosphere, in order that students can feel the charm of TCM culture in an imperceptible way. The second is to optimize the training mechanism for TCM talents. TCM colleges and universities should strengthen the joint training with other institutions in order to inject new vitality into TCM culture, and cultivate comprehensive, complex and innovative talents required by the times. At the same time, "teacher education" should be integrated into "college education", the way of talent growth ought to be optimized, teaching students in accordance with their aptitude should be emphasized, and inheriting theoretical knowledge and practical experience must be done on the basis of focusing on personalized training.

Secondly, volunteer service and skill training must be paid attention to. TCM cultural theory originates from practice, and ultimately serves practice. The foothold of inheritance and innovation of TCM should focus on providing better TCM services to the people. However, clinical practice is arranged only after two or three years of basic and professional theoretical knowledge learning for most students in colleges and universities. Consequently, there is a gap between theoretical teaching and practical training in time and space[8]. Therefore, colleges and universities of TCM should pay attention to the examination of students' practical skills, advocate medical students' early exposure to clinical practice, and guide students to master the appropriate TCM techniques such as acupuncture, massage and scraping, as well as TCM health exercises such as Wuqinxi, Taijiquan and Baduanjin in classroom teaching and clinical practice. We need to use social practice and volunteer service as the carrier to make TCM culture go deep into communities and serve the grassroots.

\subsection{Integrate Superior Resources and Expand the Radiation Radius}

In inheriting and innovating TCM culture, medical colleges and universities should not only strengthen their internal strength, but also attach importance to the cooperation with affiliated hospitals, pharmaceutical enterprises and other organizations. Through the integration of superior resources, they can form a joint force for development, and gradually expand the leading force, influence and radiation of TCM culture.
In the first place, we need to rely on the affiliated hospital to improve scientific research capabilities. The affiliated hospital is the clinical teaching base and practice base for medical students. It undertakes the heavy responsibility of clinical medicine teaching, scientific research and talent training, and is an indispensable organic component of medical colleges and universities[9] TCM colleges and universities should make full use of affiliated hospitals to publicize TCM culture and accelerate the transformation of cultural theory to scientific research results, so as to enhance the hard strength of culture. It is expected to form a system of practice teaching bases, including affiliated hospitals, teaching hospitals, practice hospitals, and community practice teaching bases. On the basis of both school and college education, the platform of affiliated hospitals will be used to expand the cultural radiation radius of TCM and enhance the cultural appeal and cohesion.

Next, it is necessary to build plantation bases and strengthen school-enterprise cooperation. The medicinal botanical garden of colleges and universities has the functional value of education and scientific research, biodiversity protection, germplasm resource preservation, beautification of the environment, popularization of Chinese medicine culture, leisure tourism, Which is an important part of the school-running characteristics and cultural communication of Chinese medicine colleges[10]. TCM colleges and universities should make full use of medicinal botanical gardens internally to make them a practical base for Chinese medicine students to recognize and learn medicines and a window for cultural publicity and display; Externally, the development of Chinese medicinal materials industry and school-enterprise cooperation should be strengthened. It is better to actively organize experts to use WeChat group, Tencent conference and other network teaching platforms to organize network training on TCM industry planting and processing technology for TCM planting enterprises and cooperatives, in order to expand the breadth and depth of TCM cultural publicity in the process of serving local cultural industries.

\subsection{Increase Publicity and Promotion to Speed up the International Process}

Above all, we should attach importance to the development and utilization of classical culture. General Secretary Xi Jinping pointed out that TCM embodies the health concepts and practical experience of the Chinese nation for thousands of years, and is the key to opening the treasure house of Chinese civilization. At the same time, he emphasized the need to follow the law of TCM development, inherit its essence, and maintain integrity and innovation. Therefore, when we inherit the culture of TCM, we should stick to the dialectical thinking, take its essence and discard its dross. Because of the abundance of traditional Chinese books and the difficulty in identifying traditional Chinese characters, the inheritance and development of traditional Chinese culture is hindered to some extent. Therefore, how to actively guide college students to simplify the complex, eliminate the false and 
retain the true, and inherit and carry forward the TCM culture with critical thinking is imminent. TCM colleges and universities should make full use of the advantages of talents and cultural resources, organize famous TCM practitioners to speed up the translation of TCM classics, collate their diagnosis and treatment experience, and compile record books of famous prescriptions, to the end that the excellent culture of Chinese medicine can be passed on from generation to generation. In addition, it is necessary to collect folk prescriptions and secret recipes with exact curative effects to enrich the cultural content of TCM hospitals. We will accelerate the integration of traditional culture with modern science and technology, establish TCM digital libraries, cultural museums and cultural corridors, and increase publicity and promotion in the form of favorites.

It is recommended to insist to the combination of "bringing in" and "going out". With the proposal of the "One Belt And One Road" initiative and the "Healthy China" strategy, especially its outstanding performance in COVID-19, the advantage of TCM knowledge in disease prevention and treatment, health care and rehabilitation has gradually won recognition from the international community. As the main base for cultural dissemination, TCM colleges and universities should seize the development opportunities in the new era and continue to the combination of "bringing in" and "going out" so that TCM culture can shine on the international stage. On the one hand, the strategy of "bringing in" should be carried out. By sending young backbone talents and managers of TCM to foreign countries for further study and exchange of medical skills, it is advocated to actively carry out international academic exchanges of TCM, and to learn excellent medical theories and techniques in an open and inclusive spirit, with the aim of injecting fresh blood into TCM culture. On the other hand, we will stick to the "going out" strategy. Through establishing Confucius Institutes of TCM in foreign countries, selling TCM cultural products (such as TCM sacs and aromatherapy), and expanding the scale of TCM students, TCM culture will go to the world.

Last but not least, we ought to make use of the Internet to innovate ways of spreading TCM culture. The rapid development of the Internet has provided a broader prospect for the spread of TCM culture. TCM colleges and universities should actively explore and innovate the new model of "Internet + TCM culture", and expand the influence of TCM culture by using big data and Internet technology. Through the establishment of an information platform for the international exchange of TCM culture, the development of online health consultation services on mobile apps or special websites, and the production of short videos of TCM knowledge, TCM classic culture will be displayed in the form of new media and new technologies, and TCM culture will eventually be revitalized.

\section{Conclusion}

TCM is a traditional treasure of the Chinese nation. TCM institutions of higher learning need to play their role in inheriting and innovating TCM culture, and take targeted measures to address such problems as the lack of distinctive cultural features, declining sense of identity and slow process of Internationalization, so that TCM can serve people around the world in a faster and better manner.

\section{Acknowledgments}

The authors would like to express their gratitude to their teachers and classmates for their help and guidance.

Supported by the Consultation Research Project of Hubei Institute of China Engineering Science and Technology Development Strategy in 2020: Research on Development Strategy of Traditional Chinese Medicine and Comprehensive Health Industry in Hubei Province

\section{References}

1. Song Jinglin, Wen Xiang.On the status and role of traditional Chinese medicine culture inheritance and innovation in traditional Chinese medicine colleges [J].International Journal of Traditional Chinese Medicine,2012,34(12):1134-1137.

2. Kuang Lin, Zhang Jiamin. The Cultural Identity of Traditional Chinese Medicine in the Universities of Chinese Medicine[J]. Education Modernization, 2020, 7(25):70-72+108.

3. Chen Xiaohan Lan Hai Huang Zejuan, et al.Research on Ways to Cultivate Students' Self-Conscious Confidence in Culture in TCM Colleges[J].Journal of Chengdu University of Traditional Chinese Medicine(Educational Science Edition), 2018, 20(03): 93-95.

4. Wei Ke, Cao Yuan, Li Kuigang.Developing Ways for Excellent Chinese Traditional Culture in University: Takes the Colleges and Universities of Traditional Chinese Medicine as Example[J].Medical Education Research and Practice,2015,23(04):628-631.

5. Cao Hongxin. Traditional Chinese medicine belongs to China and the world[J]. People's Tribune, 2016(34): 29.

6. Liao Xiaojian.Strategy of International Cultural Communication in Traditional Chinese Medicine Colleges-Based on the Belt and Road Initiative[J]. China Continuing Medical Education, 2017,9(07):3234.

7. Duan Zhiguang. On the cultural confidence education of Traditional Chinese Medicine in college students[J]. Medical Education Management, 2019, 5(6):485-489.

8. Sun Dan, Zheng Nan, Li Hewei, et al.Probe on ways of training Chinese medicine talents under the background of Traditional Chinese Medicine Law[J].China Medical Herald,2019,16(13):66-69.

9. Ji Xiaohui, Tang Wen, Wang Jinfan, et al.The status and role of affiliated hospitals in higher medical education[J].Jiangsu Higher Education,2003(4):3840. 
10. Zhang Shangzhi, Wang Ying, Yuan Jihong. Environmental Education Functions and Implementary Approaches of Medicinal Botanical Garden in Colleges And Universities[J]. Pharmaceutical Education, 2014,30(2):54-57. 